\title{
Medicaid Payment Mechanisms: Impact on Medication Adherence and Health Care Service Utilization in Type 2 Diabetes Enrollees
}

\author{
Manjiri Pawaskar, Ph.D., Steven Burch, Ph.D., ${ }^{2}$ Eric Seiber, Ph.D., ${ }^{3}$ Milap Nahata, M.S., Pharm.D., \\ Ala laconi, M.S., and Rajesh Balkrishnan, Ph.D. ${ }^{5}$
}

\begin{abstract}
The purpose of this retrospective cohort study was to examine the impact of the type of health plan (capitated vs. fee for service [FFS]) on outcomes (medication adherence and health care service utilization) in type 2 diabetes Medicaid enrollees. Subjects were 8581 Medicaid enrollees with type 2 diabetes who newly started oral pharmacotherapy and were followed for 6 months before and 12 months after the index antidiabetic medication to collect data on medication adherence and health care service utilization. Multiple log-linear regression analysis was used to predict medication adherence while negative binomial regressions were used to examine health care service utilization. Medication adherence was found to be significantly lower for patients in capitated plans $(5 \%, P<0.05)$. Moreover, patients in capitated plans were associated with $14 \%$ more hospitalizations and $16 \%$ increased odds of emergency room visits, but $27 \%$ fewer outpatient visits compared to those in FFS plans (all $P<0.05$ ). Although Medicaid programs use capitated managed care plans primarily as a costcontainment strategy, these plans may not be cost-effective for the long-term management of chronic conditions such as diabetes. (Population Health Management 2010;13:209-218)
\end{abstract}

\section{Introduction}

D IABETES IS A LEADING CAUSE OF MORBIDITY AND MORTALITY that affects $8 \%$ of the US population. ${ }^{1}$ It is a chronic progressive disease associated with a high risk of a number of serious microvascular and macrovascular complications. The total annual economic cost of diabetes in 2007 was estimated to be $\$ 174$ billion, of which $\$ 116$ billion was spent on direct medical expenditures, including $\$ 27$ billion to directly treat diabetes, $\$ 58$ billion to treat diabetes-related chronic complications, and $\$ 31$ billion in excess general medical costs. $^{2}$

The chronic nature of diabetes entails self-management and continuous medication adherence. Poor adherence to oral antidiabetic drugs (OADs) has been associated with the development of complications, disease progression, hospitalizations, premature disability, and mortality. ${ }^{3-5}$ Although medication adherence is crucial to achieve glycemic control, adherence rates to OADs were significantly low (ranging from $36 \%$ to $93 \%$ ) and adherence rates to insulin therapy vary from $62 \%$ to $64 \%$ in the United States. ${ }^{5}$ The costs associated with poor adherence have been estimated to approach $\$ 100$ billion per year. $^{3}$

Several factors affect patient adherence to medications. Insurance coverage/type of health plan plays a key role in providing access to essential health care services. With no or limited insurance coverage, patients who use more drugs face increasing out-of-pocket costs, which may result in decreased adherence. ${ }^{6-8}$ The access to pharmaceutical innovation is also mediated by the patient's primary source of health insurance coverage. Patients with public insurance (Medicare and Medicaid) are less likely to receive newer medications for the management of diabetes. ${ }^{9}$

Traditionally, Medicaid programs have paid providers primarily on a fee-for-service (FFS) basis. FFS is the financing method that pays physicians and hospitals for each service they provide. FFS health insurance plans typically allow patients to obtain care from physicians or hospitals of their

\footnotetext{
${ }^{1}$ Eli Lilly and Company, Indianapolis, Indiana.

${ }^{2}$ GlaxoSmithKline, Research Triangle Park, North Carolina.

${ }^{3}$ College of Public Health, The Ohio State University, Columbus, Ohio.

${ }^{4}$ College of Pharmacy, The Ohio State University, Columbus, Ohio.

${ }^{5}$ Center for Medication Use, Policy, and Economics, University of Michigan, Ann Arbor, Michigan.
} 
choice, but in return for this flexibility they may pay higher co-payments or deductibles. ${ }^{10}$ However, there has been an increasing trend toward managed care plans. ${ }^{11}$ Although, there are different types of managed care programs, Medicaid is increasingly adopting capitated managed care plans as a cost containment strategy. ${ }^{11}$ Capitation is defined as a method of payment wherein a fixed price is paid to providers to provide health care services to each enrolled client for a specified time period. ${ }^{12}$

The literature has shown conflicting impact of capitated managed care programs on patient outcomes. Randomized clinical trials did not find any significant differences in health outcomes of chronically mentally ill Medicaid recipients in capitated vs. traditional FFS plans. ${ }^{13}$ However, other studies showed that capitated health plans were associated with a significant reduction in hospitalization rates, length of stay, and associated costs when compared with FFS plans in Colorado, Utah, and California Medicaid programs. ${ }^{14-16}$ On the contrary, the Maryland State Medicaid program found that FFS coverage not only improved ambulatory care but also contained costs associated with avoidable hospitalization for pediatric populations. ${ }^{17}$

Data are lacking on health outcomes for patients with chronic conditions (eg, diabetes) in capitated plans in the Medicaid population. ${ }^{6,13,17}$ Particularly, the effect of type of health plan (such as capitation) on medication adherence and health care service utilization on type 2 diabetes patients is uncertain. Taking into account the limited amount of health care resources and growing health care expenditures, examining the effect of type of health plan on outcomes will be helpful to policy makers to make informed decisions regarding appropriate adoption of reimbursement policies and effective allocation of limited health care resources for this vulnerable population. Hence, the primary objective of this study was to examine the association between type of health plan (FFS vs. capitated) and economic outcomes (medication adherence and health care service utilization) in type 2 diabetes Medicaid enrollees.

\section{Methods}

\section{Study design}

This was a retrospective case-control study design comprising 8 State Medicaid data licensed from Thomson Medstat. The data were from 8 different states, including at least 1 state from each region of the United States. ${ }^{18}$ The database consists of pooled health care utilization data for approximately 7.4 million Medicaid enrollees from 1999 to 2005. It includes medical (outpatient and inpatient services), drug, and long-term care claims, and eligibility records for these enrollees. The database is Health Insurance Portability and Accountability Act compliant and features encrypted member and service provider identification numbers. For the purposes of this study, the Medicaid database was updated and queried for the period of July 1, 2002 to December 31, 2005.

\section{Study population}

The following inclusion criteria were used:

1. Patients between 18 to 64 years of age;

2. A diagnosis of type 2 diabetes (International Classification of Diseases, Ninth Revision code 250.0x-250.9x, where $\mathrm{x}=0$ or 2) during July 1, 2002 to December 31, 2005;

3. An OAD index medication fill (January 31, 2001, through December 31, 2004);

4. Continuous enrollment during the follow-up period: patients were followed for 6 months before and 12 months after the date of the first OAD prescription fill (the index date);

5. Moreover, patients were required to be OAD therapy naive (no fills for any OAD during the 6 months before the index date). OAD medications were grouped by therapeutic class, including metformin, sulfonylureas (SUs), thiazolidinediones (TZDs), alpha-glucosidase inhibitors, and meglitinides. Patients who used more than 1 OAD medication were classified as combination therapy.

The following exclusion criteria were used:

1. Patients who were on insulin therapy at any time during the follow-up period (ie, 6 months pre- and 12 months post-index), which also includes patients who started insulin at any time after the index claim for an OAD. These patients were excluded because the claims data set does not provide sufficient information to calculate medication adherence for insulin therapy, making it impossible to examine the primary objective (adherence to insulin) in patients on insulin therapy. Medication adherence for patients on insulin therapy also is substantially different from those on oral medications because of the complexity of the dosing regimen. Additionally, these are high-risk patients whose level of severity is higher compared to those on oral therapy and, thus, they do not make a comparable cohort.

2. Patients with diagnosis of type 1 or gestational diabetes;

3. Patients who switched from one type of health plan to another (eg, from capitated to FFS or vice versa) during the follow-up period.

The final breakdown of sample size after applying all inclusion and exclusion criteria is illustrated in Figure 1.

\section{Measurement and outcomes}

Medication adherence. Pharmacy records have shown predictive validity as a measure of cumulative exposure and gaps in medication supply ${ }^{19}$; hence, prescription refill patterns were used to derive measures of medication adherence. Medication possession ratio (MPR) was used to measure medication adherence. MPR was calculated as the days of OAD medication supply dispensed divided by the number of days in the observation period. ${ }^{19-21}$ The observation period for this study was 12-month follow-up period. The number of days a person was in a hospital was subtracted from the denominator because any drug taken during this time is provided by the hospital and is not captured in the pharmacy records. Information on all filled prescriptions was extracted from the pharmaceutical claims data file. Each record contains information on the medication dispensed including date of dispensation, quantity dispensed, and days supply of medication.

$M P R=\#$ of days supply of OAD medication in the postindex period/\# of days in the study period (365 days). 
Step 1: There were 7.4 million patients in the Medstat MarketScan 8 State Medicaid Database for years 1999 to 2005.

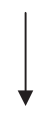

Step 2: Approximately 488,343 patients who were dual eligible (both Medicaid and Medicare) were excluded from the study.

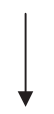

Step 3: Medical claims were examined to identify patients with a diagnosis of type 2 diabetes in the database. It produced 403,093 patient records.

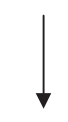

Step 4: Enrollee IDs of 403,093 were compared against the outpatient pharmaceutical claims database to identify claims for oral antidiabetic medications using National Drug Codes for the time period January 1, 2003 to December 31, 2004. We found 157,090 patients who were using some type of oral pharmacotherapy after the diagnosis in this time frame.

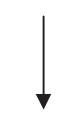

Step 5: Only patients who were between the ages of 18 and 64 years as of the index date in 2003 were included. This resulted in a cohort of 101,346 patients.

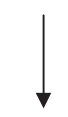

Step 6: From this cohort, we identified 44,761 patients who newly started oral antidiabetic medication during 2003 to 2004 by examining pharmacy claims data 6 months before the index prescription. A total of 56,585 patients who were using oral antidiabetic medication prior to the index date were excluded from the study.

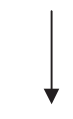

Step 7: We excluded patients who used insulin therapy and combination therapy any time during the study period, which resulted in a patient cohort of 22,866 .

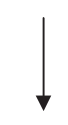

Step 8: Only patients with continuous Medicaid eligibility for 6 months before and 12 months after the index date were retained in the data set with the help of monthly eligibility indicator. This resulted in 8,930 patients.

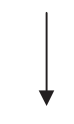

Step 9: Finally, patients who were in either a fee-for-service or a capitated health plan for the entire follow-up period were examined further. A total of 349 patients had both fee-for-service and capitated plans in the follow-up period and were excluded from the study. This resulted into a final cohort of 8,581 patients.

FIG. 1. Steps involved in the creation of final study cohort (after applying all inclusion and exclusion criteria). 
Type of health plan (FFS vs. capitation). The MarketScan Medicaid database provides a patient-level indicator variable for the type of health plan each patient is enrolled in. Medicaid has classified plans into 2 groups ${ }^{18}$ :

1) Capitation: represents capitated managed care plan in which managed care organizations receive a fixed amount of payment per enrollee per month. All or some services offered by managed care organizations are paid on a capitated basis.

2) Fee-for-service (FFS): represents health plans that pay providers or physicians on the basis of services rendered. There is no incentive for the patient to use a particular list of providers. Coverage is handled by only 1 policy, with a deductible and coinsurance. The patient-level variable is coded as 1 for capitation and 0 for FFS health plan.

Health care service utilization. Patients' complete health care service utilization was followed during the post-index period and events were identified using Current Procedural Terminology/ICD-9 codes and service codes. Health care service utilization was measured as the number of hospitalizations, the odds of emergency room (ER) visits, and the number of outpatient visits.

Demographic variables. Patient's age, sex, race/ethnicity.

Clinical variables: Diabetes/Comorbidity severity. Deyo modification of Charlson Comorbidity Index (DCCI) was used to measure severity of comorbidities. ${ }^{22,23}$ This index is a simple, readily applicable method of estimating risk of death from comorbid disease. DCCI has been validated for several other health outcome estimations besides death. ${ }^{24,25}$ Health care utilization in the pre-index period was used as a proxy for severity of diabetes. ER visits, hospitalization visits, and visits to endocrinologists in the pre-index period were captured from the medical claims.

Medication/therapy related variables. The number of prescription medications, number of therapeutic classes of medications, the class of index OAD medications prescribed, and the year the index medication was prescribed were also measured as covariates.

\section{Statistical analysis}

Descriptive statistics were performed to compare baseline characteristics. Continuous data were described by means and standard deviations, and nominal and categorical data were described by frequencies and percentages. Unadjusted demographic, clinical, and medication characteristic comparisons between groups were completed using independent sample $t$ tests for evaluation of continuous variables and chisquare tests for categorical variables. The data were analyzed using STATA software version 9.2 (Stata Corp, College Station, TX). ${ }^{26}$ All univariate, bivariate, and multivariate analyses were conducted at a set $\alpha$ priori level of significance (0.05).

The ordinary least square (OLS) regression was used to evaluate the relationship between the type of health plan and medication adherence after controlling for potential covari- ates. The primary independent variable was the type of health plan (FFS vs. capitation). Other covariates included in the model were demographic (age, sex, race/ethnicity), clinical variables such as DCCI, health care resource utilization in pre-index period (hospitalizations, ER visits), and therapy-related variables (number of prescriptions, therapeutic class of medications, class of index OAD medication, year of index medication prescribed).

The normality was determined using the Shapiro-Wilk test. $^{27}$ The heteroskedasticity was determined using the White test. The data were also examined for multicollinearity (ie, a linear relationship between predictor variables). A variation inflation factor of $<10$ was considered to indicate absence of multicollinearity.

The logistic regression model was used to determine the odds of ER visits. The standard negative binomial regression model was used to predict the number of outpatient visits while the zero-inflated negative binomial regression model was used to predict the number of hospitalizations. The adequacy of model was examined using the Vuong test. ${ }^{26}$ The log retransformed value of the dependent variables used in the model, $\mathrm{g}^{*}$, was calculated using the correction by Halverson and Palmquist estimator with a modification by Kennedy. ${ }^{28,29}$

\section{Results}

\section{Patient characteristics (Table 1)}

The study cohort consists of a total of 8581 patients with type 2 diabetes. Patients had mean age of 47.32 years (standard deviation [SD]: 10.93) and comprised $67.9 \%$ females $(n=5831)$. The majority of patients were white $(60.3 \%)$ followed by African American (27.8\%); only $2.6 \%$ were Hispanic. A total of $3763(43.9 \%)$ patients were enrolled in capitated health plans and $4818(56.2 \%)$ were enrolled in traditional FFS plans.

The bivariate analysis showed that the mean age of patients enrolled in capitated plans (46.06 [SD: 11.24]) was slightly lower than that of patients enrolled in FFS plans (48.30 [SD: 10.58]; $P<0.001$ ). The proportion of females $(72.7 \%)$ was significantly higher in capitated plans compared to FFS plans $(64.2 \% ; P<0.0001)$. Capitated plans had a higher percentage of African Americans (36.8\%) than FFS plans $(20.8 \%$; $P<0.001)$. When we looked at health care service utilization in the pre-index period, visits to endocrinologists were slightly higher in capitated plans than in FFS plans $(1.4 \%$ vs. $0.2 \% ; P<0.0001)$. The number of ER visits was slightly lower in capitated plans compared to FFS plans (39.8\% vs. $42.3 \% ; P<0.018$ ); however there was no significant difference in number of hospitalizations.

\section{Medication adherence (Table 2)}

The OLS regression model showed that after adjusting for all covariates, patients in capitated plans had 5\% lower medication adherence compared to those in FFS plans $(P<0.05)$. Other covariates in the model were also predictors of medication adherence. Patients ages 30-50 years and 50-64 years had higher medication adherence (55\% and $73 \%$, respectively; $P<0.0001$ ) than those ages $18-29$ years old. Females, African Americans, and patients with previous ER visits and hospitalizations had lower medication 
Table 1. Comparisons of Categorical and Continuous Patient Characteristics Across Health Plans

\begin{tabular}{|c|c|c|c|c|}
\hline Variable & Measure & $\begin{array}{l}\text { Capitation }(\mathrm{n}=3763) \\
\mathrm{n}(\%) / \text { mean }(S D)\end{array}$ & $\begin{array}{c}F F S(\mathrm{n}=4818) \\
\mathrm{n}(\%) / \text { mean }(S D)\end{array}$ & P value \\
\hline \multirow[t]{3}{*}{ Age group (years) } & $18-29$ & 367 (9.75) & $283(5.87)$ & \multirow[t]{3}{*}{$<0.0001$} \\
\hline & $30-49$ & $1,782(47.36)$ & $2,119(43.98)$ & \\
\hline & $50-64$ & $1,614(42.89)$ & $2,416(50.15)$ & \\
\hline \multirow[t]{2}{*}{ Sex } & Male & $1,026(27.27)$ & $1,724(35.78)$ & \multirow[t]{2}{*}{$<0.0001$} \\
\hline & Female & $2,737(72.73)$ & $3,094(64.22)$ & \\
\hline \multirow[t]{4}{*}{ Race/Ethnicity } & White & $1,747(46.43)$ & $3,428(71.15)$ & \multirow[t]{4}{*}{$<0.0001$} \\
\hline & African American & $1,386(36.83)$ & $1,003(20.82)$ & \\
\hline & Hispanics & $147(3.91)$ & $74(1.54)$ & \\
\hline & Others & $483(12.84)$ & $313(6.50)$ & \\
\hline Visit to endocrinologist & (yes/no) & $53(1.41)$ & $8(0.17)$ & $<0.0001$ \\
\hline Hospitalization & (yes/no) & $605(45.15)$ & $735(54.85)$ & 0.298 \\
\hline ER visit & (yes/no) & $1,915(39.75)$ & $1,591(42.28)$ & 0.018 \\
\hline \multirow{7}{*}{$\begin{array}{l}\text { Index class of antidiabetic } \\
\text { medication }\end{array}$} & Sulfonylurea & $931(24.74)$ & $1,214(25.20)$ & \multirow[t]{7}{*}{0.129} \\
\hline & Biguanides & $2,162(57.45)$ & $2,533(52.57)$ & \\
\hline & Thiazolidinediones & $304(8.08)$ & $634(13.16)$ & \\
\hline & Alpha glucosidase & $11(0.29)$ & $11(0.23)$ & \\
\hline & Meglitinides & $47(1.25)$ & $51(1.06)$ & \\
\hline & Sulfonylurea-biguanide & $212(5.63)$ & $236(4.9)$ & \\
\hline & TZD-biguanides & $96(2.55)$ & $139(2.89)$ & \\
\hline \multirow[t]{2}{*}{ Index year } & 2003 & $1869(49.67)$ & $2355(48.88)$ & \multirow[t]{2}{*}{0.468} \\
\hline & 2004 & $1894(50.33)$ & $2463(51.12)$ & \\
\hline Age in years & & $46.06(11.24)$ & $48.30(10.58)$ & $<0.0001$ \\
\hline Charlson comorbidity index & & $1.69(2.18)$ & $1.97(2.30)$ & $<0.0001$ \\
\hline Total number of prescriptions & & $25.66(22.35)$ & $29.93(26.46)$ & $<0.0001$ \\
\hline $\begin{array}{l}\text { Total number of therapeutic } \\
\text { class of medications }\end{array}$ & & $7.58(5.00)$ & $8.35(5.74)$ & $<0.0001$ \\
\hline Number of outpatient visits & & 8.17 (12.40) & $10.73(16.81)$ & $<0.0001$ \\
\hline
\end{tabular}

Chi-square test of independence for categorical variables; the independent sample $t$ test for continuous variables.

$\mathrm{ER}=$ emergency room; $\mathrm{FFS}=$ fee-for-service; $\mathrm{SD}=$ standard deviation .

adherence $(P<0.0001)$. When categorized by the type of OAD therapy, biguanide users had $5 \%$ higher medication adherence as compared to SU users $(P<0.05)$. Alphaglucosidase and meglitinide users had significantly lower medication adherence compared to SU users $(47 \%$ and $36 \%$, respectively, all $P<0.0001)$. There was no significant difference in adherence between TZD, fixed dose combination therapy, and SU users.

We also evaluated the effect of type of health plan on adherent (MPR $\geq 80 \%$ ) and nonadherent groups (MPR $<80 \%$ ) by performing logistic regression. Patients in capitated health plans had $11 \%$ lower odds of being adherent to medications compared to those in FFS plans after controlling for all the covariates (95\% confidence interval [CI]: 0.82, 0.98). This analysis also confirmed that females (22\%, 95\% CI: 0.71, 0.86) and African Americans (33\%, 95\% CI: 0.61, 0.75) were less likely to be adherent to therapy. Patients who used alphaglucosidase inhibitors (68\%, 95\% CI: 0.11 to 0.88$)$ and meglitinides (65\%, 95\% CI: 0.22 to 0.56$)$ were less likely to be adherent to therapy compared to those who used SU.

\section{Estimation of hospitalizations across the health plans (Table 3)}

The zero-inflated negative binomial regression model revealed that patients in capitated plans were associated with a $13.9 \%$ increase in the number of hospitalizations when compared to patients in FFS plans $(\beta=0.13,95 \%$ CI: 0.02 , $0.23)$. Patients with prior ER visits ( $45 \%)$ and hospitalizations (75\%) were associated with a greater number of hospitali- zations compared to those without these events $(95 \% \mathrm{CI}$ : $0.40,0.63$ and $0.58,0.82$, respectively). A higher Charlson score and more therapeutic classes of medication used in the pre-index period was also associated with an increased number of hospitalizations $(P<0.05)$.

\section{Estimation of ER visits across the health plans (Table 3)}

A multiple logistic regression was employed to measure the association between type of health plan and the likelihood of emergency room visit, the results of which are illustrated in Table 3. Patients in capitated health plans were $16 \%$ more likely to have an ER visit than those in FFS plans (95\% CI: 1.06, 1.28). Those who were in the age group 30-49 and 50-64 years were less likely to have an emergency room visit compared to those between $18-29$ years (95\% CI: $(0.51,0.73)$ and $(0.33,0.47)$, respectively). African Americans (28\%, 95\% CI: 1.15, 1.42) and patients with higher Charlson scores (7\%, 95\% CI: 1.04, 1.09) were also associated with an increased risk of ER visits.

\section{Estimation of outpatient visits across the health plans (Table 4)}

Table 4 shows that patients enrolled in capitated health plans had $27 \%$ fewer outpatient visits compared to those in FFS plans $(P<0.0001)$. Those ages $50-64$ years had $23 \%$ fewer outpatient visits, while African Americans had 9\% fewer outpatient visits $(P<0.0001)$. Similarly, patients who used meglitanides, TZD, and fixed dose combination therapy 
Table 2. Comparison of Medication Adherence Rates Across Health Plans

\begin{tabular}{|c|c|c|c|c|}
\hline \multirow[b]{2}{*}{ Variables } & \multicolumn{2}{|c|}{$\operatorname{MPR}(\log )^{\psi}$} & \multicolumn{2}{|c|}{$\begin{array}{c}\text { Adherent } \\
(M P R \geq 80 \%)^{\dagger}\end{array}$} \\
\hline & $B(S E)$ & $95 \% C I$ & $O R(S E)$ & $95 \% C I$ \\
\hline Type of health plan capitation & $-0.04(0.02)$ & $(-0.07,-0.01)^{*}$ & $0.89(0.04)$ & $(0.82,0.98)^{*}$ \\
\hline \multicolumn{5}{|l|}{ Age group: } \\
\hline $30-49$ years & $0.41(0.034)$ & $(0.34,0.47)^{* *}$ & $2.45(0.26)$ & $(1.99,3.02)^{* * *}$ \\
\hline 50-64 years & $0.55(0.035)$ & $(0.47,0.61)^{* *}$ & $3.68(0.38)$ & $(2.94,4.46)^{* *}$ \\
\hline Female & $-0.08(0.02)$ & $(-0.12,-0.04)^{* *}$ & $0.78(0.39)$ & $(0.71,0.86)^{* *}$ \\
\hline Black race & $-0.11(0.02)$ & $(-0.14,-0.07)^{* *}$ & $0.67(0.04)$ & $(0.61,0.75)^{* * *}$ \\
\hline Charlson comorbidity score & $-0.01(0.01)$ & $(-0.02,0.01)$ & $0.98(0.01)$ & $(0.96,1.00)$ \\
\hline Event of ER visit & $-0.16(0.02)$ & $(-0.19,-0.12)^{* *}$ & $0.62(0.03)$ & $(0.56,0.68)^{* *}$ \\
\hline Event of hospitalization & $-0.11(0.02)$ & $(-0.16,-0.07)^{* *}$ & $0.84(0.05)$ & $(0.74,0.94)^{*}$ \\
\hline Visit to endocrinologist & $-0.11(0.10)$ & $(-0.31,0.08)$ & $0.81(0.23)$ & $(0.46,1.42)$ \\
\hline $\begin{array}{l}\text { No. of therapeutic class } \\
\text { of medications }\end{array}$ & $0.02(0.01)$ & $(0.02,0.02)^{*}$ & $1.05(0.01)$ & $(1.05,1.07)^{* *}$ \\
\hline \multicolumn{5}{|l|}{ Index class of OAD } \\
\hline Biguanides & $0.05(0.02)$ & $(0.01,0.09)^{*}$ & $0.92(0.05)$ & $(0.83,1.03)$ \\
\hline Alpha glucosidase & $-0.64(0.17)$ & $(-0.96,-0.302)^{* *}$ & $0.32(0.16)$ & $(0.11,0.88)^{* *}$ \\
\hline Meglitinides & $-0.45(0.08)$ & $(-0.61,-0.289)^{* *}$ & $0.35(0.08)$ & $(0.22,0.56)^{* *}$ \\
\hline Thiazolidinediones & $0.04(0.03)$ & $(-0.025,0.097)$ & $1.11(0.09)$ & $(0.94,1.29)$ \\
\hline Fixed dose combination & $0.04(0.03)$ & $(-0.03,0.11)$ & $0.87(0.08)$ & $(0.72,1.04)$ \\
\hline Index year: 2004 & $0.02(0.02)$ & $(-0.01,0.06)$ & $0.99(0.04)$ & $(0.91,1.08)$ \\
\hline Constant & $-1.14(0.04)$ & $(-1.22,-1.06)^{* *}$ & - & - \\
\hline
\end{tabular}

*significance at 0.05 level, ${ }^{* *}$ significance at 0.0001 level, Reference groups: Age group 18-29 years; Male sex; All other races; Sulfonylurea users.

${ }^{\dagger}$ A multivariable logistic regression; ${ }^{\psi}$ An ordinary least square regression; $95 \% \mathrm{CI}=95 \%$ confidence interval; $\mathrm{ER}=\mathrm{emergency} \mathrm{room;}$ $\mathrm{MPR}=$ medication possession ratio; $\mathrm{OR}=$ odds ratio; $\mathrm{SE}=$ standard error; $\mathrm{OAD}=$ oral antidiabetic drugs.

Table 3. Comparison of Hospitalizations And Emergency Room Visits Across Health Plans

\begin{tabular}{|c|c|c|c|c|}
\hline \multirow{2}{*}{$\begin{array}{l}\text { Dependent variable } \rightarrow \\
\text { Predictor variables } \downarrow\end{array}$} & \multicolumn{2}{|c|}{$\begin{array}{c}\text { Number of } \\
\text { hospitalizations }\end{array}$} & \multicolumn{2}{|c|}{$\begin{array}{l}\text { Likelihood of } \\
\text { ER visits }\end{array}$} \\
\hline & $B(S E)$ & $95 \% \mathrm{CI}$ & $O R(S E)$ & $95 \% \mathrm{CI}$ \\
\hline Type of health plan capitation & $0.13(0.05)$ & $(0.02,0.23)^{*}$ & $1.17(0.06)$ & $(1.06,1.28)^{*}$ \\
\hline \multicolumn{5}{|l|}{ Age group: } \\
\hline 30-49 years & $-0.47(0.09)$ & $(-0.67,-0.27)^{* *}$ & $0.61(0.05)$ & $(0.51,0.73)^{* *}$ \\
\hline 50-64 years & $-0.58(0.10)$ & $(-0.77,-0.36)^{* *}$ & $0.39(0.06)$ & $(0.33,0.47)^{* *}$ \\
\hline Female & $-0.15(0.06)$ & $(-0.07,0.16)$ & $1.11(0.06)$ & $(0.99,1.22)$ \\
\hline Black race & $-0.03(0.06)$ & $(-0.22,0.03)$ & $1.28(0.08)$ & $(1.15,1.42)^{* *}$ \\
\hline Charlson comorbidity score & $0.18(0.01)$ & $(0.15,0.19)^{* *}$ & $1.07(0.09)$ & $(1.04,1.09)^{* *}$ \\
\hline Event of ER visit & $0.37(0.06)$ & $(0.40,0.63)^{* *}$ & $2.96(0.15)$ & $(2.67,3.29)^{* * *}$ \\
\hline Event of hospitalization & $0.55(0.06)$ & $(0.58,0.82)^{* *}$ & $1.06(0.06)$ & $(0.93,1.20)$ \\
\hline Visit to endocrinologist & $0.18(0.28)$ & $(-0.38,0.72)$ & $1.36(90.04)$ & $(0.76,2.42)$ \\
\hline $\begin{array}{l}\text { No. of therapeutic class } \\
\text { of medications }\end{array}$ & $0.04(0.004)$ & $(0.022,0.04)^{* *}$ & $1.10(0.01)$ & $(1.09,1.11)^{* * *}$ \\
\hline \multicolumn{5}{|l|}{ Index class of OAD } \\
\hline Biguanides & $-0.12(0.06)$ & $(-0.23,0.02)$ & $1.11(0.09)$ & $(0.99,1.25)$ \\
\hline Alpha glucosidase & $-1.28(0.68)$ & $(-2.72,0.05)$ & $1.79(0.19)$ & $(0.66,4.89)$ \\
\hline Meglitinides & $-0.07(0.23)$ & $(-0.52,0.42)$ & $0.88(0.20)$ & $(0.56,1.37)$ \\
\hline Thiazolidinediones & $0.06(0.09)$ & $(-0.12,0.24)$ & $1.07(0.09)$ & $(0.89,1.26)$ \\
\hline Fixed dose combination & $-0.12(0.11)$ & $(-0.34,0.10)$ & $1.05(0.06)$ & $(0.87,1.27)$ \\
\hline Index year: 2004 & $-0.06(0.05)$ & $(-0.13,0.08)$ & $1.01(0.04)$ & $(0.92,1.11)$ \\
\hline Constant & $-1.59(0.12)$ & $(-1.92,-1.27)^{* *}$ & - & - \\
\hline
\end{tabular}

*significance at 0.05 level; **significance at 0.0001 level, Reference groups: Age group 18-29 years; Male sex; All other races; Sulfonylurea users.

${ }^{\dagger}$ A multivariable logistic regression; ${ }^{\psi}$ The zero inflated negative binomial regression $95 \% \mathrm{CI}=95 \%$ confidence interval; OR $=$ odds ratio; $\mathrm{SE}=$ standard error; $\mathrm{OAD}=$ oral antidiabetic drugs. 
were associated with a higher number of outpatient visits compared to those who used SU $(P<0.0001)$.

\section{Discussion}

The study included type 2 diabetes patients between 18 to 64 years of age who used some type of oral pharmacotherapy in Medicaid settings. The study consists of a higher proportion of older adults (mean 47 years). The age distribution is consistent with the literature indicating a higher prevalence of diabetes with older age. ${ }^{30}$ The database consisted of a higher proportion of female patients compared to other observational studies. The distribution of the type of health plans was uniform in this study population (44\% FFS and 56\% capitated plans). The findings are consistent with the literature that shows an increasing trend toward capitated managed care plans in Medicaid programs. According to the Kaiser Family Foundation, approximately $45 \%$ of Medicaid enrollees received services under capitated managed care. ${ }^{31}$

The study found significant differences in OAD medication adherence by type of health plan. Patients covered by capitated plans had 5\% lower mean OAD adherence compared to patients in FFS plans. The limited prescription drug benefits offered under capitation could be the primary reason for this finding. Although most Medicaid programs offer this type of coverage, it varies widely from state to state. Capitated health plans provide a fixed dollar amount per member per month for all pharmacy services. These caps allow health plans to provide some benefits to a large patient population at a predictable level of total expenditures for the plan in a market in which medication costs are increasing rapidly. Once that limit is reached, patients must pay all pharmacy costs out-of-pocket in order to get their medications.

The New Hampshire Medicaid program, which had imposed a cap on prescription benefits, experienced a $35 \%$ reduction in drug use when compared with the control group (New Jersey program without any cap). ${ }^{32}$ Moreover, other studies showed that patients who exceed this cap were 2 to 3 times more likely to discontinue medications. ${ }^{33,34}$ Hence, restricted prescription coverage offered under capitation could be associated with lower medication adherence by Medicaid beneficiaries compared with FFS. Conversely, coverage under FFS plans is based upon the type and number of prescription medications or any pharmacy services used. Patients generally pay some or no co-payments for medication. In Medicaid programs, co-payments are very low and generally range from $\$ 0.50-\$ 3$ per refill.

Patients in capitated health plans had a significantly higher number of hospitalizations and ER visits compared to those in FFS plans. Capitation may lead to undertreatment, substitution of inadequate health services, cost shifting to other service systems, and poor treatment, which in turn may result in poor patient outcomes and excessive use of health care resources. ${ }^{35,36}$ Our study also showed that patients in capitated plans had significantly lower medication adherence, which could be further associated with significantly higher health care service utilization. Several studies have shown that poor medication adherence is associated with higher health care utilization and costs. ${ }^{3,4,37}$

Patients in capitated health plans had a significantly lower number of outpatient visits compared to those in FFS plans.
Table 4. Comparison of Outpatient Visits Across Health Plans

\begin{tabular}{|c|c|c|}
\hline \multirow{2}{*}{$\begin{array}{l}\text { Dependent variable } \rightarrow \\
\text { Predictor variables } \downarrow\end{array}$} & \multicolumn{2}{|c|}{$\begin{array}{c}\text { Number of outpatient } \\
\text { visits }{ }^{\psi}\end{array}$} \\
\hline & $\beta(S E)$ & $95 \% \mathrm{CI}$ \\
\hline $\begin{array}{l}\text { Type of health plan } \\
\text { capitation }\end{array}$ & $-0.24(0.02)$ & $(-0.29,-0.20)^{* *}$ \\
\hline \multicolumn{3}{|l|}{ Age group: } \\
\hline 30-49 years & $-0.01(0.04)$ & $(-0.10,0.07)$ \\
\hline 50-64 years & $-0.15(0.04)$ & $(-0.24,-0.06)^{* *}$ \\
\hline Female & $0.02(0.02)$ & $(-0.02,0.07)$ \\
\hline Black race & $-0.09(0.02)$ & $(-0.14,-0.04)^{*}$ \\
\hline Charlson score & $0.06(0.01)$ & $(0.05,0.07)^{* *}$ \\
\hline Event of ER visit & $0.01(0.005)$ & $(0.05,0.04)$ \\
\hline Event of hospitalization & $0.06(0.02)$ & $(0.01,0.11)^{*}$ \\
\hline $\begin{array}{l}\text { Event of outpatient visit in } \\
\text { pre-index period }\end{array}$ & $1.09(0.06)$ & $(1.02,1.15)^{* *}$ \\
\hline Visit to endocrinologist & $-0.14(0.08)$ & $(-0.4,0.12)$ \\
\hline $\begin{array}{l}\text { No. of therapeutic class } \\
\text { of medications }\end{array}$ & $0.02(0.002)$ & $(0.02,0.03)^{* *}$ \\
\hline \multicolumn{3}{|l|}{ Index class of OAD } \\
\hline Biguanides & $0.01(0.02)$ & $(-0.05,0.05)$ \\
\hline Alpha glucosidase & $0.02(0.21)$ & $(-0.41,0.45)$ \\
\hline Meglitinides & $0.33(0.10)$ & $(0.12,0.54)^{* *}$ \\
\hline Thiazolidinediones & $0.19(0.04)$ & $(0.11,0.26)^{* *}$ \\
\hline Fixed dose combination & $0.09(0.04)$ & $(0.01,0.18)^{*}$ \\
\hline Index year: 2004 & $0.05(0.02)$ & $(0.01,0.09)^{*}$ \\
\hline Constant & $1.75(0.06)$ & $(1.64,1.86)^{*}$ \\
\hline
\end{tabular}

*significance at $p<0.05$ level, ${ }^{* *}$ significance at $P<0.0001$ level, Reference groups: Age group 18-29 years; Male sex; Other races; Sulfonylurea users.

"The negative binomial regression.

$95 \% \mathrm{CI}=95 \%$ confidence interval; $\mathrm{ER}=$ emergency room; $\mathrm{OAD}=$ oral antidiabetic medications; $\mathrm{OR}=$ odds ratio; $\mathrm{SE}=$ standard error.

This could be due to inadequate capitation rates or it could take place when a medication cap is reached. The literature has shown mixed findings. Some studies indicate that access to specialty care or ambulatory care was decreased under capitated plans. ${ }^{16,38}$ However, others studies showed improved outpatient visits after capitation ${ }^{39}$ (Iowa $^{40}$ and Maryland ${ }^{41}$ ). Capitation provides direct financial incentives to manage utilization, thereby motivating providers and health plans to use health care resources more effectively. However, this might lead to a shorter duration of treatment or limited patient follow-up or visits. ${ }^{42}$ Several other research studies have shown that, under capitation, physicians tend to make more referrals to colleagues when the limit is reached. ${ }^{43}$ Therefore, it could be that lower medication adherence and poor monitoring might be responsible for higher health care utilization for patients in capitated health plans. Improved medication adherence has been associated with better glycemic levels and a reduced risk of hospitalization and ER visits ${ }^{3,44}$ and is therefore of paramount importance to patients with diabetes.

\section{Limitations}

These results should be interpreted with caution, taking into account the study limitations. The 8 State Medstat MarketScan database does not disclose the identity of the 
states that contributed the data. Hence, we could not compare differences in study outcomes across states. Moreover, the database does not provide any information on type or level of capitation or pharmacy benefit caps and, as a result, we could not examine variations across the different capitated health plans. Results may not be generalizable to other patient populations (eg, Medicare, commercial third-party). Furthermore, the observational nature of the study design does not permit causal inference of results.

The study could not examine the associations between certain sociodemographic characteristics (eg, education, income, socioeconomic status), clinical factors (eg, HbA1C, body mass index), behavioral factors (eg, social support), psychological factors (eg, patient health beliefs, perceived severity of disease, perceived benefits of treatment), and medication adherence because data were not available. However, health care utilization and Charlson Comorbidity Index scores in the pre-index period were used as a proxy for the severity of diabetes. The study excluded patients on insulin therapy because data were not available to adequately measure insulin adherence. This may introduce selection bias as these patients may be sicker or more nonadherent.

Cost data are not captured under capitated health plans, and hence the association between type of health plan and total health care cost could not be evaluated. To avoid potential misclassification bias resulting from billing or coding errors, total health care utilization was examined (captured as encounter data), such as hospitalizations and ER visits, as opposed to diabetes-specific utilization.

\section{Implications}

Despite these limitations, this study has some important implications for health care providers and policy makers. Insurance coverage plays a key role in providing access to essential health care services. All patients covered by Medicaid should receive equal access to health care services, especially all the necessary medications for the effective management of diabetes. In our study, patients in capitated health plans had significantly lower medication adherence to OAD therapy compared to their FFS counterparts. Medication adherence plays a critical role in the effective management of diabetes because it requires continuous medication use. Differences in medication adherence across type of health plan raise important concerns regarding benefits offered under capitated health plans. Further investigation is warranted to identify potential gaps in OAD adherence across plan type.

Capitated health plans must develop adequate strategies to improve access to health care services for patients with diabetes. Medicaid beneficiaries are low-income patients and, therefore, are very sensitive to increased out-of-pocket expenses. As a result, it is essential that clinicians actively identify patients with diabetes who are facing medication cost pressures and assist them by modifying their medication regimens, helping them understand the importance of each prescribed medication, providing them with information on sources of low-cost drugs, and linking patients with coverage programs. There is a need for policy makers to reconsider the guidelines for coverage under capitation.

Capitated plans must improve access to care by placing increased emphasis on outpatient care in order to reduce reliance on inpatient and institutionalized care. Disease management interventions are also required, such as the tailored medication regimens, lifestyle modifications, selfmanagement, continuity of treatment and monitoring, and patient education over time. Physicians, nurses, pharmacists, and dietitians play a key role in providing these services to patients and effectively monitoring diabetes. However, restricted access to care and limited outpatient care may hinder these activities and further affect medication management and medication adherence.

The main goal of the capitated payment system is to provide incentives to reduce reliance on institutional and inpatient care in favor of outpatient care, and to increase emphasis on preventive care. The expected net result is to reduce, or at least stabilize, health care utilization. However, results from this study indicate that Medicaid capitated health plans fail to achieve these objectives. Disparities in medication adherence, access to care, and health care utilization warrant raising awareness of the health care gap among broad sectors including payers, policy makers, health care providers, patients, health plan purchasers, and society at large.

\section{Conclusion}

This study clearly indicates that patients with type 2 diabetes who are covered under Medicaid capitated managed care plans had significantly lower medication adherence compared to those in FFS plans. Additionally, these patients had significantly fewer outpatient visits, which further reflects limited access to health care services and continuity of treatment. Patients in capitated health plans were associated with a significantly greater number of hospitalizations and ER visits compared to patients in FFS plans, which reflects excessive use of health care resources. Although Medicaid uses capitated managed care plans primarily as a cost-containment strategy, they may not be cost-effective for the long-term management of chronic conditions such as diabetes. Policy makers and third-party payers should consider the unique needs of patients with type 2 diabetes and facilitate access to medications and care for better management of the disease.

\section{Author Disclosure Statement}

Drs. Pawaskar, Burch, Seiber, Nahata, and Balkrishnan, and Ms Iaconi disclosed no conflicts of interest.

\section{References}

1. American Diabetes Association. Economic costs of diabetes in the US in 2007. Diabetes Care 2008a;31:596-615.

2. American Diabetes Association. Standards of medical care in diabetes-2008. Diabetes Care 2008b;31:S12-S54.

3. Hughes DA, Bagust A, Haycox A, Walley T. The impact of non-compliance on the cost-effectiveness of pharmaceuticals: A review of the literature. Health Econ 2001;10:601-615.

4. Balkrishnan R, Rajagopalan R, Camacho FT, Huston SA, Murray FT, Anderson RT. Predictors of medication adherence and associated health care costs in an older population with type 2 diabetes mellitus: a longitudinal cohort study. Clin Ther 2003;25:2958-2971.

5. Cramer JA. A systematic review of adherence with medications for diabetes. Diabetes Care 2004;27:1218-1224.

6. Piette JD, Wagner TH, Potter MB, Schillinger D. Health insurance status, cost-related medication underuse, and out- 
comes among diabetes patients in three systems of care. Med Care 2004;42:102-109.

7. Soumerai SB, Mah C, Zhang F, et al. Effects of health maintenance organization coverage of self-monitoring devices on diabetes self-care and glycemic control. Arch Intern Med 2004;164:645-652.

8. Jackson JE, Doescher MP, Saver BG, Fishman P. Prescription drug coverage, health, and medication acquisition among seniors with one or more chronic conditions. Med Care 2004;42:1056-1065.

9. Skaer TL, Sclar DA, Robison LM. Trends in the prescribing of oral agents for the management of type 2 diabetes mellitus in the United States, 1990-2001: Does type of insurance influence access to innovation? Diabetes Educ 2006;32: 940-953.

10. US Office of Personnel Management. Federal Benefits Program Glossary. Available at http://www.opm.gov/ insure/health/about/glossary.asp. Accessed on January 10, 2008.

11. Friedman E. The compromise and the afterthought. Medicare and Medicaid after 30 years. JAMA 1995;274:278-282.

12. Gold M, Nelson L, Lake T, Hurley R, Berenson R. Behind the curve: A critical assessment of how little is known about arrangements between managed care plans and physicians. Med Care Res Rev 1995;52:307-341.

13. Bloom JR, Hu TW, Wallace N, et al. Mental health costs and access under alternative capitation systems in Colorado. Health Serv Res 2002;37:315-340.

14. Reed SK, Hennessy KD, Mitchel OS, Babigian HM. A mental health capitation program: II. Cost-benefit analysis. Hosp Community Psychiatry 1994;45:1097-1103.

15. Wyant D, Christianson J, Coleman B. The financial impact on community mental health centers of capitated contracts with Medicaid: the Utah Prepaid Mental Health Plan. Community Ment Health J 1999;35:135-152.

16. Gadomski A, Jenkins P, Nichols M. Impact of a Medicaid primary care provider and preventive care on pediatric hospitalization. Pediatrics 1998;101:E1.

17. Lurie N, Moscovice IS, Finch M, Christianson JB, Popkin MK. Does capitation affect the health of the chronically mentally ill? Results from a randomized trial. JAMA 1992;267:3300-3304.

18. MarketScan ${ }^{\circledR}$ research databases user guide and data dictionary. Multi-state Medicaid database 1995-2005 edition. Available at: http://marketscan.thomsonreuters.com/. Accessed on December 1, 2007.

19. Steiner JF, Koepsell TD, Fihn SD, Inui TS. A general method of compliance assessment using centralized pharmacy records. Description and validation. Med Care 1998;26: 814-823.

20. Farmer KC. Methods for measuring and monitoring medication regimen adherence in clinical trials and clinical practice. Clin Ther 1999;21:1074-1090.

21. Hess LM, Raebel MA, Conner DA, Malone DC. Measurement of adherence in pharmacy administrative databases: A proposal for standard definitions and preferred measures. Ann Pharmacother 2006;40:1280-1288.

22. Charlson ME, Pompei P, Ales KL, MacKenzie CR. A new method of classifying prognostic comorbidity in longitudinal studies: Development and validation. J Chronic Dis 1987;40:373-383.

23. Deyo RA, Cherkin DC, Ciol MA. Adapting a clinical comorbidity index for use with ICD-9-CM administrative databases. I Clin Epidemiol 1992;45:613-619.
24. Romano PS, Roos LL, Jollis JG. Adapting a clinical comorbidity index for use with ICD-9-CM administrative data: Differing perspectives. J Clin Epidemiol 1993;46:1075-1079.

25. D'Hoore W, Sicotte C, Tilquin C. Risk adjustment in outcome assessment: the Charlson comorbidity index. Methods Inf Med 1993;32:382-387.

26. Stata. Data analysis and statistical software. Reference manual 9. College Station, TX: Stata Corp; 2006.

27. D'Agostino AN. An omnibus test of normality for moderate and large size samples. Biometrika 1971;58:341-348.

28. Halverson R, Palmquist R. The interpretation of dummy variables in semilogarithmic equations. Am Econ Rev 1980; 70:474-475.

29. Kennedy P. Estimation with correctly interpreted dummy variables in semilogarithmic equations. Am Econ Rev 1981; 71:801.

30. Centers for Disease Control and Prevention. National Diabetes Fact Sheet: General Information and National Estimates on Diabetes in the United States, 2005. Atlanta, GA: US Department of Health and Human Services, Centers for Disease Control and Prevention; 2005.

31. Kaiser Family Foundation. Medicaid and managed care: fact sheet. 2001. Available at http://www.kff.org/medicaid/ upload/Medicaid-and-Managed-Care-Fact-Sheet.pdf. Accessed on January 11, 2008.

32. Soumerai SB, McLaughlin TJ, Ross-Degnan D, Casteris CS, Bollini P. Effects of a limit on Medicaid drug reimbursement benefits on the use of psychotropic agents and acute mental health services by patients with schizophrenia. N Engl J Med 1994;331:650-655.

33. Cox ER, Jernigan C, Coons SJ, Draugalis JL. Medicare beneficiaries' management of capped prescription benefits. Med Care 2001;39:296-301.

34. Tseng CW, Brook RH, Keeler E, Steers WN, Mangione CM. Cost-lowering strategies used by Medicare beneficiaries who exceed drug benefit caps and have a gap in drug coverage. JAMA 2004;292:952-960.

35. Mechanic D, Aiken LH. Capitation in mental health: Potentials and cautions. New Dir Ment Health Serv 1989:5-18.

36. Berwick DM. Quality of health care. Part 5: Payment by capitation and the quality of care. N Engl J Med 1996; 335:1227-1231.

37. Pladevall M, Williams LK, Potts LA, Divine G, Xi H, Lafata JE. Clinical outcomes and adherence to medications measured by claims data in patients with diabetes. Diabetes Care 2004;27:2800-2805.

38. Balkrishnan R, Hall MA, Mehrabi D, Chen GJ, Feldman SR, Fleischer AB Jr. Capitation payment, length of visit, and preventive services: Evidence from a national sample of outpatient physicians. Am J Manag Care 2002;8:332-340.

39. Deck DD, McFarland BH, Titus JM, Laws KE, Gabriel RM. Access to substance abuse treatment services under the Oregon Health Plan. JAMA 2000;284:2093-2099.

40. McCary D, Argeriou M. The Iowa managed substance abuse care plan: access,utilization, and expenditures for Medicaid recipients. J Behav Health Serv Res 2003;30:18-25.

41. Ettner SL, Denmead G, Dilonardo J, Cao H, Belanger AJ. The impact of managed care on the substance abuse treatment patterns and outcomes of Medicaid beneficiaries: Maryland's HealthChoice program. J Behav Health Serv Res 2003;30:41-62.

42. Galanter M, Keller DS, Dermatis H, Egelko S. American Society of Addiction Medicine. The impact of managed care on substance abuse treatment: A problem in need of 
solution. A report of the American Society of Addiction Medicine. Recent Dev Alcohol 2001;15:419-436.

43. Chaix-Couturier C, Durand-Zaleski I, Jolly D, Durieux P. Effects of financial incentives on medical practice: Results from a systematic review of the literature and methodological issues. Int J Qual Health Care 2000;12:133-142.

44. Brown JB, Nichols GA, Glauber HS, Bakst A. Ten-year follow up of antidiabetic drug use, nonadherence, and mortality in a defined population with type 2 diabetes mellitus. Clin Ther 1999;21:1045-1057.
Address correspondence to: Rajesh Balkrishnan, Ph.D.

Director, Center for Medication Use, Policy and Economics School of Pharmacy and Public Health

University of Michigan

428 Church Street

Ann Arbor, Michigan 48104

E-mail: rbalkris@umich.edu 